\title{
DAMAGE MONITORING OF 2D SiC-SiC COMPOSITES UNDER MONOTONIC AND CYCLIC LOADING/UNLOADING USING ACOUSTIC EMISSION AND NATURAL FREQUENCY
}

\author{
XIAOJUN GUO*, JINWU, WU**, JIAN LI*, YUQI ZENG*, ${ }^{*}$ XIAOZHONG HUANG***, ${ }^{*}$ LONGBIAO LI**** \\ *AECC Hunan Aviation Powerplant Research Institute, Zhuzhou 412000, PR China \\ **Nanchang Hangkong University, Nanchang 330063, PR China \\ ***Powder Metallurgy Research Institute, Central South University Changsha, Hunan 410083, PR China \\ ****College of Civil Aviation, Nanjing University of Aeronautics and Astronautics \\ No.29 Yudao St., Nanjing 210016, PR China \\ \#E-mail: huangxzh@csu.edu.cn, 1lb451@nuaa.edu.cn
}

Submitted December 27, 2020; accepted February 1, 2021

\begin{abstract}
Keywords: Ceramic-matrix composites (CMCs), Hysteresis loops, Natural Frequency, Matrix cracking, Interface debonding, Fibers failure

In this paper, tensile damage and fracture of $2 \mathrm{D} \mathrm{SiC/SiC} \mathrm{composites} \mathrm{are} \mathrm{investigated} \mathrm{using} \mathrm{damage} \mathrm{monitoring} \mathrm{of} \mathrm{acoustic}$ emission (AE) and natural frequency. Nonlinear damage and fracture are mainly attributed to damage mechanisms of matrix cracking, interface debonding, and fibers fracture. Monotonic tensile stress-strain curves are divided into three stages based on the analysis of AE count, amplitude, and energy. Under cyclic loading/unloading, hysteresis loops appear due to internal frictional slip between the fiber and the matrix, and the natural frequency and composite modulus are obtained for different peak stress. A micromechanical tensile and cyclic loading/unloading constitutive model is adopted to predict the tensile curves. Micro damage parameters of interface debonding ratio and broken fibers fraction are used to characterize tensile damage and fracture. Relationships between natural frequency, composite modulus, interface debonding, and fibers fracture are established. Under tensile loading, the AE signal is large and concentrated mainly in the stress range of $50-100 \mathrm{MPa}$ and $150-180 \mathrm{MPa}$, which corresponds to matrix cracking and fiber fracture, respectively. When the degradation rate of natural frequency approaches 0.01, matrix cracking and interface debonding occur, however, fibers failure does not appear; when the degradation rate of natural frequency approaches 0.04 , the composite modulus decreases approximately $47 \%$ and the interface debonding ratio approaches 0.8 and the broken fibers fraction is approximately $2.2 \%$.
\end{abstract}

\section{INTRODUCTION}

Ceramic-matrix composites (CMCs) have the characteristics of low density, high temperature resistance, wear resistance and long life, which mainly include $\mathrm{C} / \mathrm{SiC}$ and $\mathrm{SiC} / \mathrm{SiC}$ composites [1-4]. The density of $\mathrm{SiC} / \mathrm{SiC}$ composite is only approximately $1 / 4-1 / 3$ of that of nickel-base superalloy, but the operating temperature is approximately $400-500{ }^{\circ} \mathrm{C}$ higher than that of the nickelbase superalloy. The development of CMC components follows the idea of "easy first, then difficult", that is, from static parts to rotating parts, from low temperature to high temperature. Priority have been given to the development of stationary parts with intermediate temperature (i.e., $700-1000{ }^{\circ} \mathrm{C}$ ) and medium load (i.e., lower than $120 \mathrm{MPa}$ ), for example, nozzle flap seal and regulator and inner cone, and then to develop stationary parts with high-temperature (i.e., $1000-1300{ }^{\circ} \mathrm{C}$ ) and medium load, such as flame tube, flame stabilizer, turbine outer ring, and guide vane, etc., and finally to develop high-pressure turbine rotor parts with higher load (i.e., higher than $120 \mathrm{MPa}$ ). At present, the entire life test of nozzle flap seal and regulator, inner cone and turbine outer ring has already been completed; the life assessment of flame tube and guide vane is in progress; the development of high pressure turbine rotor is in the verification stage. NASA, GE and other companies have developed $\mathrm{C} / \mathrm{SiC}$ turbine blisk, $\mathrm{SiC} / \mathrm{SiC}$ turbine blades and other rotor parts, and carried out preliminary tests on F110, F414, F136 aero engine platforms. Turbine rotor is the most challenging key component in the hot section of turbine engine, and the success application of CMCs on turbine rotor will have a significant impact on the development of turbine engine [7].

During application of CMC components, there exists internal process defects and damages caused by external environment and load [5, 6]. Wang et al. [7] investigated cyclic loading/unloading tensile behavior of $2 \mathrm{D} \mathrm{C} / \mathrm{SiC}$ composite and obtained the interface shear stress and thermal residual stress in the composite 
through hysteresis analysis. Li et al. [8] investigated the tensile loading/unloading stress-strain behavior of 2D $\mathrm{SiC} / \mathrm{SiC}$ composite and analyzed the matrix cracking evolution during tensile loading. It is necessary to develop damage detecting method to determine internal defects and damages. There are many types of nondestructive testing (NDT) methods applied to the internal defects and environmental damage of CMCs, including X-ray, infrared thermal imaging, microanalysis, laser holography, CT, acoustic emission (AE), electrical resistance (ER), and ultrasonic, etc. $\mathrm{Hu}$ et al. [10] investigated the vibration characteristic of 2D woven $\mathrm{SiC} / \mathrm{SiC}$ composite and predicted the macroscopic effective constants. Li [11] investigated the timedependent vibration damping behavior of fiber-reinforce CMCs at elevated temperature. The damping caused by the frictional slip between the fiber and the matrix depends on the internal damage state and environmental temperature. The natural frequency is one of the main characteristics of vibration characteristics. Bai et al. [12] investigated the natural frequency of delaminated advanced grid stiffened composite plates by hump resonance method. Li [13] performed vibration analysis of damaged $\mathrm{CMC}$ structures. When the natural frequency decreased approximately $5.47 \%$, the CMC structure was seriously damaged and in a dangerous state. However, in the research mentioned above, there are few investigations on the relationship between natural frequency and internal damage of CMCs.

The objective of this paper is to investigate tensile damage and fracture of $2 \mathrm{D} \mathrm{SiC} / \mathrm{SiC}$ composites using damage monitoring of $\mathrm{AE}$ and natural frequency. Nonlinear damage and fracture are mainly attributed to damage mechanisms of matrix cracking, interface debonding, and fibers fracture. Monotonic tensile stressstrain curves are divided into three stages based on the analysis of AE count, amplitude, and energy. Under cyclic loading/unloading, hysteresis loops appear due to internal frictional slip between the fiber and the matrix, and the natural frequency and composite modulus are obtained for different peak stress. A micromechanical tensile and cyclic loading/unloading constitutive model is adopted to predict the tensile curves. Micro damage parameters of interface debonding ratio and broken fibers fraction are used to characterize tensile damage and fracture. Relationships between natural frequency, composite modulus, interface debonding, and fibers fracture are established.

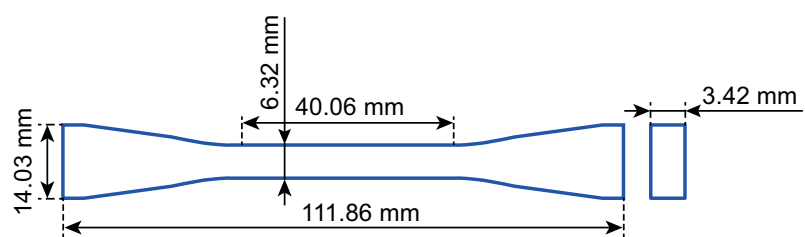

Figure 1. Tensile specimen of $2 \mathrm{D} \mathrm{SiC/SiC} \mathrm{composite.}$

\section{EXPERIMENTAL}

2D woven $\mathrm{SiC} / \mathrm{SiC}$ composite was provided by Central South University. The Boxiang ${ }^{\mathrm{TM}}$ III SiC fiber was woven into two-dimensional fiber preform. The PyC interphase was deposited on the $\mathrm{SiC}$ surface using chemical vapor infiltration (CVI) method, and the interphase thickness was approximately $150 \mathrm{~nm}$. The fabrication of $\mathrm{SiC} / \mathrm{SiC}$ composite was using the precursor infiltration

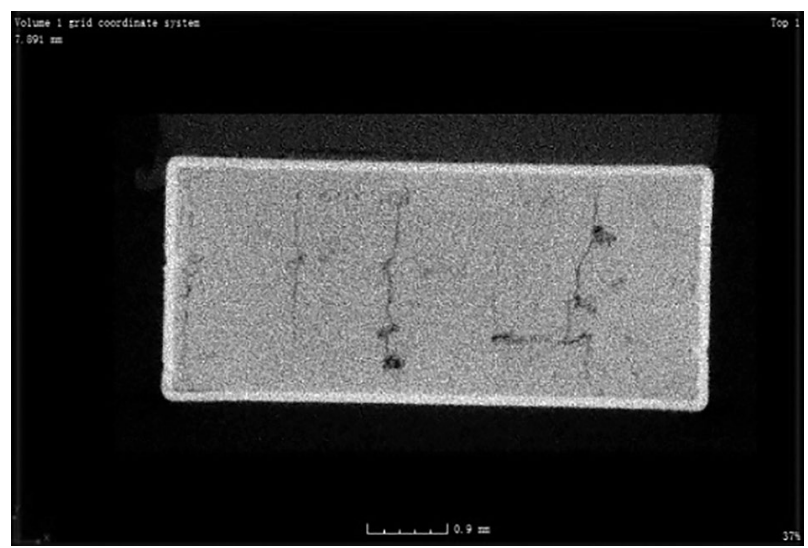

a)

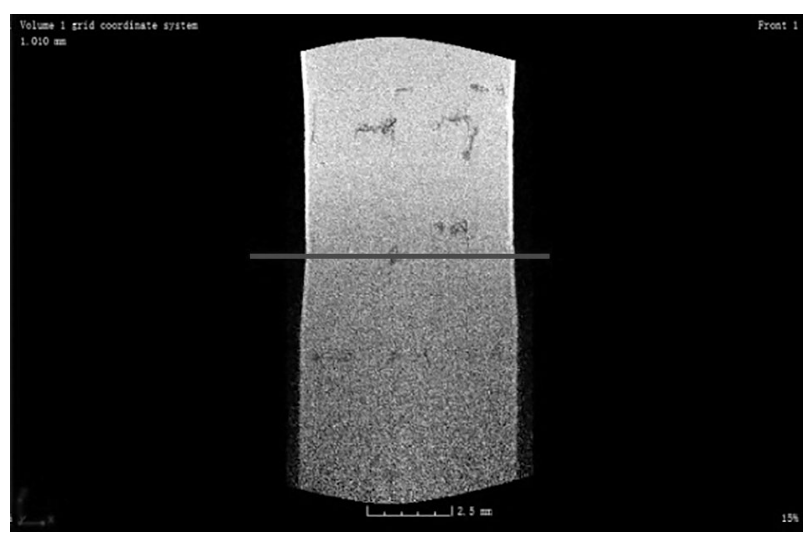

b)

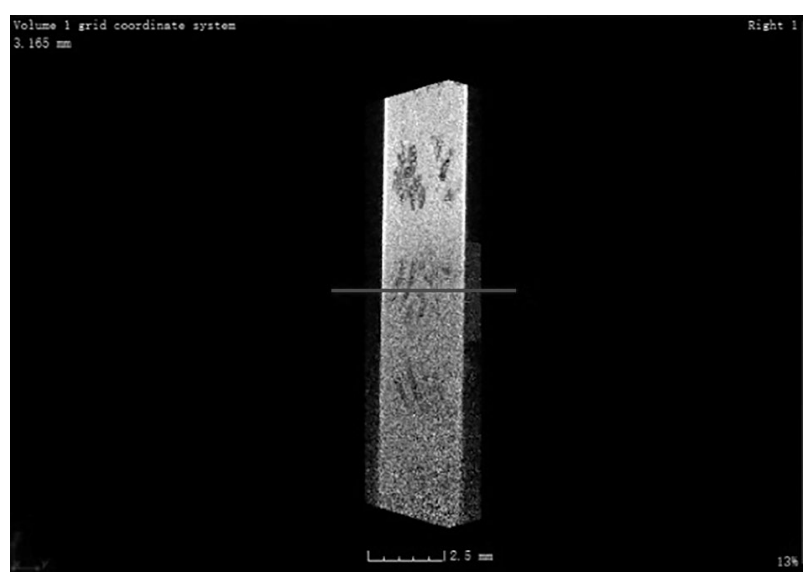

c)

Figure 2. CT scan of original composite specimen. (Continue on next page) 


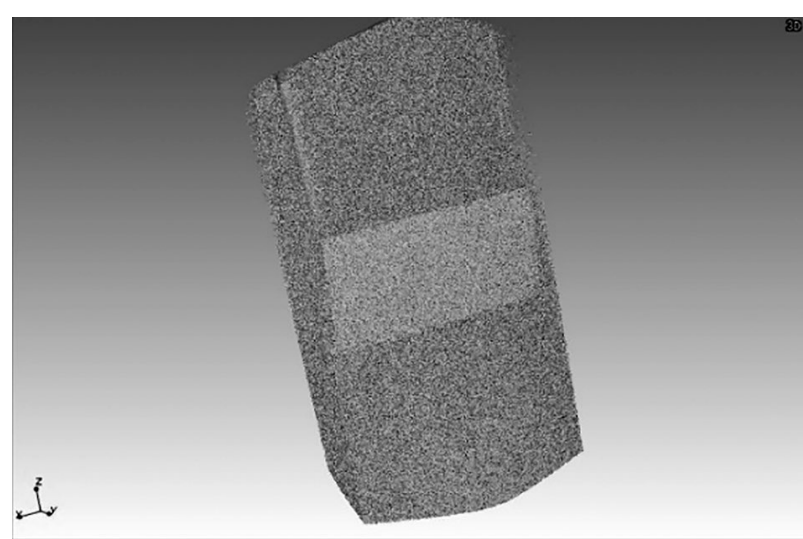

d)

Figure 2. CT scan of original composite specimen.

process (PIP) method. After fabrication, the dog-bone shaped specimens, with dimensions of $111.86 \mathrm{~mm}$ in length, $3.42 \mathrm{~mm}$ thick, and $6.32 \mathrm{~mm}$ width in the gauge section, were cut from composite panes using wire-electrode cutting, which is shown in Figure 1. The fiber volume of the composite was approximately $40 \%$. Before tensile tests, CT scan was conducted to examine the internal damages of the composite, as shown in Figure 2. It can be found that some micro matrix cracking existed in the original composite specimen.

Monotonic and cyclic loading/unloading tensile tests of $2 \mathrm{D} \mathrm{SiC} / \mathrm{SiC}$ composite were conducted on an INSTRON 8872 servo hydraulic load-frame (INSTRON Systems Corp., Boston, Massachusetts, USA), which is shown in Figure 3a. Tensile tests were conducted under displacement control with the loading rate of $0.05 \mathrm{~mm} \cdot \mathrm{min}^{-1}$. During tensile tests, the clip-on extensometer was used to obtain the composite strain, and the acoustic emission monitoring system PCI-2 (Physical Acoustics Corp., New York, USA) and R80D

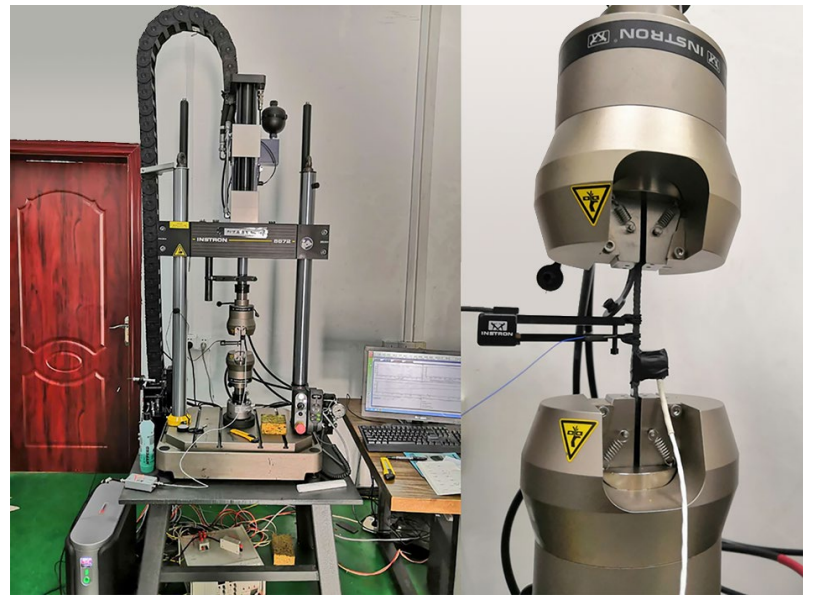

a)

b)

Figure 3. Photograph of tensile and damage monitoring system of 2D SiC/SiC composite: a) INSTRON 8872 servo hydraulic load-frame; b) the clip-on extensometer and acoustic emission probe. piezoelectric sensor were adopted to monitor damage evolution process of composite, which is shown in Figure 3b. PSV-500 laser vibration meter and piezoelectric ceramics were used to test the natural frequency of the sample, which is shown in Figure 4.

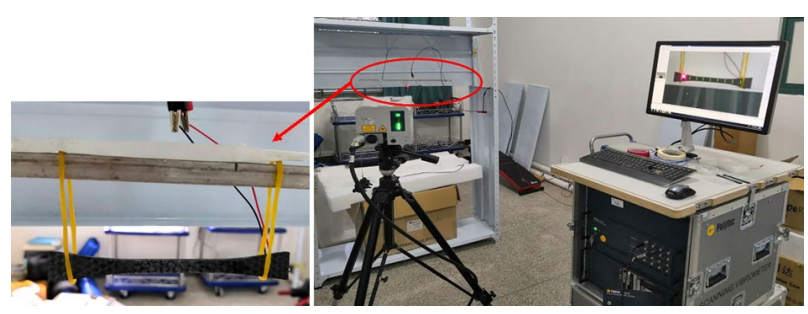

Figure 4. Natural frequency testing system.

\section{THEORETICAL}

Under cyclic loading/unloading tensile, multiple damage mechanisms of matrix cracking, interface debonding, and fibers failure contribute to the nonlinear tensile and hysteresis loops of CMCs. Li [12] developed a micromechanical approach to predict the tensile and cyclic loading/unloading hysteresis loops of fiber-reinforced CMCs.

When matrix cracking and interface debonding occur, the composite tensile constitutive relationship is [12]

$$
\begin{aligned}
\varepsilon_{\mathrm{c}} & =\frac{\sigma}{V_{\mathrm{f}} E_{\mathrm{f}}} \frac{2 l_{\mathrm{d}}}{l_{\mathrm{c}}}-\frac{\tau_{\mathrm{i}}}{E_{\mathrm{f}}} \frac{2 l_{\mathrm{d}}^{2}}{r_{\mathrm{f}} l_{\mathrm{c}}}+2 \frac{\sigma_{\mathrm{fo}}}{E_{\mathrm{f}} l_{\mathrm{c}}}\left(\frac{l_{\mathrm{c}}}{2}-l_{\mathrm{d}}\right)- \\
& -\frac{1}{\rho E_{\mathrm{f}}} \frac{2 r_{\mathrm{f}}}{l_{\mathrm{c}}}\left(\frac{V_{\mathrm{m}}}{V_{\mathrm{f}}} \sigma_{\mathrm{mo}}-2 \frac{l_{\mathrm{d}}}{r_{\mathrm{f}}} \tau_{\mathrm{i}}\right) \times \\
& \times\left[\exp \left(-\rho \frac{l_{\mathrm{c}} / 2-l_{\mathrm{d}}}{r_{\mathrm{f}}}\right)-1\right]-\left(\alpha_{\mathrm{c}}-\alpha_{\mathrm{f}}\right) \Delta \mathrm{T}
\end{aligned}
$$

where $V_{\mathrm{f}}$ and $V_{\mathrm{m}}$ are the fiber and matrix volume, $E_{\mathrm{f}}$ is the fiber elastic modulus, $l_{\mathrm{d}}$ is the interface debonding length, $l_{c}$ is the matrix crack spacing, $r_{f}$ is the fiber radius, and $\tau_{i}$ is the interfacial shear stress, $\sigma_{f o}$ and $\sigma_{m o}$ are the fiber and matrix axial stress in the interface bonding region.

When fibers failure occurs with matrix cracking and interface debonding, the composite tensile constitutive relationship is [12]

$$
\begin{aligned}
\varepsilon_{\mathrm{c}} & =\frac{\Phi}{E_{\mathrm{f}}} \frac{2 l_{\mathrm{d}}}{l_{\mathrm{c}}}-\frac{\tau_{\mathrm{i}}}{E_{\mathrm{f}}} \frac{2 l_{\mathrm{d}}^{2}}{r_{\mathrm{f}} l_{\mathrm{c}}}+\frac{2 \sigma_{\mathrm{fo}}}{E_{\mathrm{f}} l_{\mathrm{c}}}\left(\frac{l_{c}}{2}-l_{\mathrm{d}}\right)- \\
& -\frac{1}{\rho E_{\mathrm{f}}} \frac{2 r_{\mathrm{f}}}{l_{\mathrm{c}}}\left(\Phi-\sigma_{\mathrm{fo}}-2 \frac{l_{\mathrm{d}}}{r_{\mathrm{f}}} \tau_{\mathrm{i}}\right) \times \\
& \times\left[\exp \left(-\rho \frac{l_{\mathrm{c}} / 2-l_{\mathrm{d}}}{r_{\mathrm{f}}}\right)-1\right]-\left(\alpha_{\mathrm{c}}-\alpha_{\mathrm{f}}\right) \Delta \mathrm{T}
\end{aligned}
$$


where $\Phi$ is the stress carried by the intact fibers, and $\alpha_{f}$ and $\alpha_{c}$ are the fiber and composite thermal expansional coefficient, and $\Delta T$ is the temperature difference between testing and fabricated temperature.

Upon unloading/reloading, the hysteresis loops constitutive relationship for the interface partial is [12]

$$
\begin{aligned}
\varepsilon_{\text {unloading }} & =\frac{\Phi_{\mathrm{U}}}{E_{\mathrm{f}}}+4 \frac{\tau_{\mathrm{i}}}{E_{\mathrm{f}}} \frac{l_{y}^{2}}{r_{\mathrm{f}} l_{\mathrm{c}}}-\frac{\tau_{\mathrm{i}}}{E_{\mathrm{f}}} \frac{\left(2 l_{y}-l_{\mathrm{d}}\right)\left(2 l_{y}+l_{\mathrm{d}}-l_{\mathrm{c}}\right)}{r_{\mathrm{f}} l_{\mathrm{c}}}- \\
& -\left(\alpha_{\mathrm{c}}-\alpha_{\mathrm{f}}\right) \Delta \mathrm{T} \\
\varepsilon_{\text {reloading }}= & \frac{\Phi_{R}}{E_{\mathrm{f}}}-4 \frac{\tau_{\mathrm{i}}}{E_{\mathrm{f}}} \frac{l_{z}^{2}}{r_{\mathrm{f}} l_{\mathrm{c}}}+4 \frac{\tau_{\mathrm{i}}}{E_{\mathrm{f}}} \frac{\left(l_{y}-2 l_{z}\right)^{2}}{r_{\mathrm{f}} l_{\mathrm{c}}} \\
& +2 \frac{\tau_{\mathrm{i}}}{E_{\mathrm{f}}} \frac{\left(l_{\mathrm{d}}-2 l_{y}+2 l_{z}\right)\left(l_{\mathrm{d}}+2 l_{y}-2 l_{z}-l_{\mathrm{c}}\right)}{r_{\mathrm{f}} l_{\mathrm{c}}}- \\
& -\left(\alpha_{\mathrm{c}}-\alpha_{\mathrm{f}}\right) \Delta \mathrm{T}
\end{aligned}
$$

where $\Phi_{U}$ and $\Phi_{R}$ are the intact fiber stress upon unloading and reloading, $l_{y}$ and $l_{\mathrm{z}}$ are the interface counter slip length and interface new slip length.

When the interface complete debonding occurs, the hysteresis loops constitutive relationship is [12]

$$
\begin{aligned}
\varepsilon_{\text {unloading }} & =\frac{\Phi_{\mathrm{U}}}{E_{\mathrm{f}}}+4 \frac{\tau_{\mathrm{i}}}{E_{\mathrm{f}}} \frac{l_{y}^{2}}{r_{\mathrm{f}} l_{\mathrm{c}}}-2 \frac{\tau_{\mathrm{i}}}{E_{\mathrm{f}}} \frac{\left(2 l_{y}-l_{\mathrm{c}} / 2\right)^{2}}{r_{\mathrm{f}} l_{\mathrm{c}}}- \\
& -\left(\alpha_{\mathrm{c}}-\alpha_{\mathrm{f}}\right) \Delta \mathrm{T} \\
\varepsilon_{\text {reloading }}= & \frac{\Phi_{R}}{E_{\mathrm{f}}}-4 \frac{\tau_{\mathrm{i}}}{E_{\mathrm{f}}} \frac{l_{z}^{2}}{r_{\mathrm{f}} l_{\mathrm{c}}}+4 \frac{\tau_{\mathrm{i}}}{E_{\mathrm{f}}} \frac{\left(l_{y}-2 l_{z}\right)^{2}}{r_{\mathrm{f}} l_{\mathrm{c}}}- \\
& -2 \frac{\tau_{\mathrm{i}}}{E_{\mathrm{f}}} \frac{\left(l_{\mathrm{c}} / 2-2 l_{y}+2 l_{z}\right)^{2}}{r_{\mathrm{f}} l_{\mathrm{c}}}-\left(\alpha_{\mathrm{c}}-\alpha_{\mathrm{f}}\right) \Delta \mathrm{T}
\end{aligned}
$$

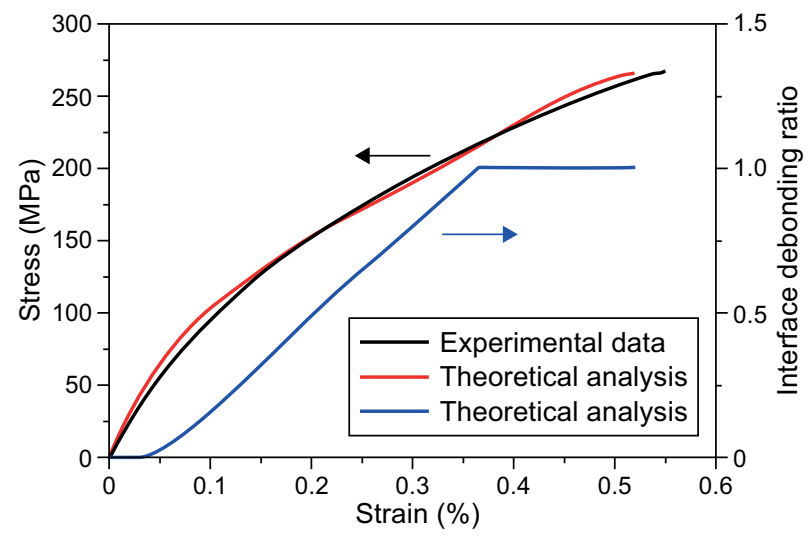

a)
In the present analysis, the degradation rate of natural frequency $(\varphi)$, the degradation rate of composite modulus $(\psi)$, and the interface debonding ratio $(\eta)$ are defined as:

$$
\begin{gathered}
\phi=1-\frac{f(\sigma)}{f_{0}} \\
\psi=1-\frac{E(\sigma)}{E_{0}} \\
\eta=\frac{2 l_{\mathrm{d}}}{l_{\mathrm{c}}}
\end{gathered}
$$

where $f_{0}$ and $E_{0}$ denote the composite initial natural frequency and modulus.

\section{RESULTS AND DISCUSSION}

Figure 5 shows experimental and predicted tensile stress-strain curves, interface debonding ratio, and AE energy versus loading time curves of $2 \mathrm{D} \mathrm{SiC} / \mathrm{SiC}$ composite. Materials properties of $\mathrm{SiC} / \mathrm{SiC}$ composite are listed in Table 1. Under tensile loading, the composite exhibits obviously nonlinear behavior due to multiple damage mechanisms of matrix cracking, interface debonding, and fibers broken. The composite elastic modulus was approximately $E_{\mathrm{c}}=132 \mathrm{GPa}$. Based on the monitoring of acoustic emission, the tensile curve can be divided into three stages, including:

- Stage I, which starts from initial loading to applied stress $\sigma_{\mathrm{mc}}=50 \mathrm{MPa}$. At this stage, the AE count and AE energy are in the middle level, the duration and amplitude are basically stable after a period of rising range, and the frequency range of $\mathrm{AE}$ is wide, which indicates that the specimen gradually produces damage in the initial stage of loading, but the energy of single damage is small, mainly due to initial micro cracking and partial interface debonding.

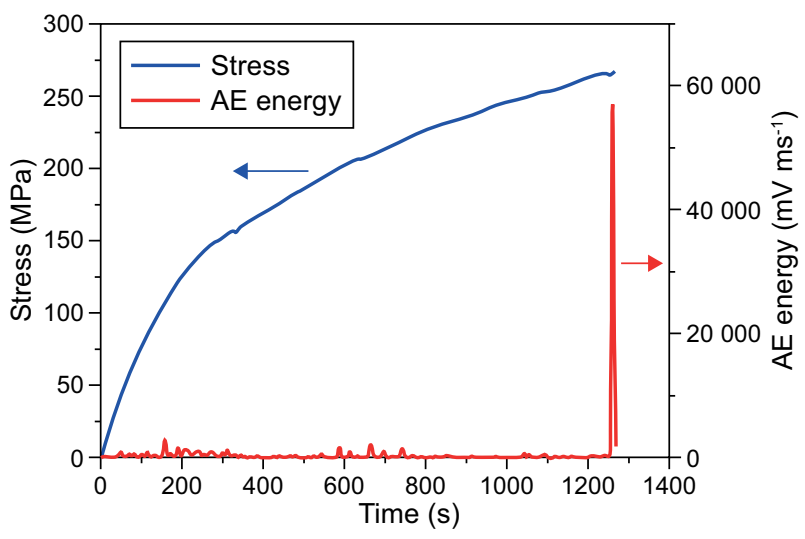

b)

Figure 5. Experimental and predicted tensile stress-strain and interface debonding ratio curves (a) and the stress and acoustic energy versus loading time curves of $2 \mathrm{D} \mathrm{SiC} / \mathrm{SiC}$ composite (b). 
- Stage II, which lies in the stress range from $\sigma_{\mathrm{mc}}=$ $=50 \mathrm{MPa}$ to $\sigma_{\mathrm{sat}}=215 \mathrm{MPa}$. At this stage, the AE count is in the middle level, and the AE energy is relatively high. The frequency of AE signals lie mainly between $0-70 \mathrm{kHz}$ and $130-220 \mathrm{kHz}$, which indicates that the matrix cracks continue to propagate and a small amount of fiber fracture occurs.

Table 1. Material properties of 2D SiC/SiC composite.

\begin{tabular}{|c|c|}
\hline Items & Value \\
\hline$V_{\mathrm{f}} \ldots \ldots$ & …........ 0.4 \\
\hline$E_{\mathrm{f}} \ldots \ldots$ & $\ldots 280 \mathrm{GPa}$ \\
\hline$E_{\mathrm{m}} \ldots \ldots$ & ... $425 \mathrm{GPa}$ \\
\hline$r_{\mathrm{f}} \ldots \ldots \ldots$ & ........6 $6 \mu \mathrm{m}$ \\
\hline$\alpha_{\mathrm{f}} \ldots \ldots \ldots$ & $4.5 \times 10^{-6}{ }^{\circ} \mathrm{C}$ \\
\hline$\alpha_{\mathrm{m}} \ldots \ldots$ & $4.6 \times 10^{-6}{ }^{\circ} \mathrm{C}$ \\
\hline$\Delta T \ldots \ldots$ &..$-1000^{\circ} \mathrm{C}$ \\
\hline$\tau_{i} \ldots \ldots \ldots$ & .....17 MPa \\
\hline
\end{tabular}

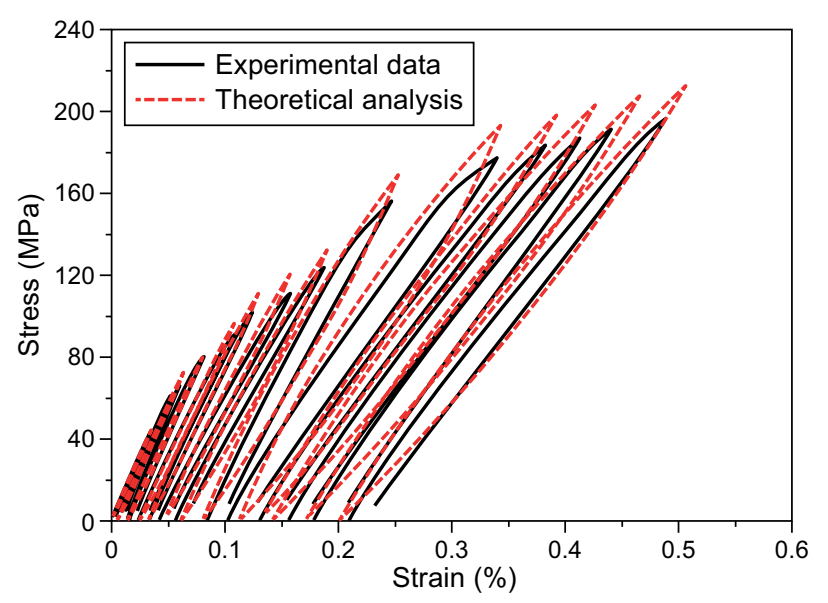

a)

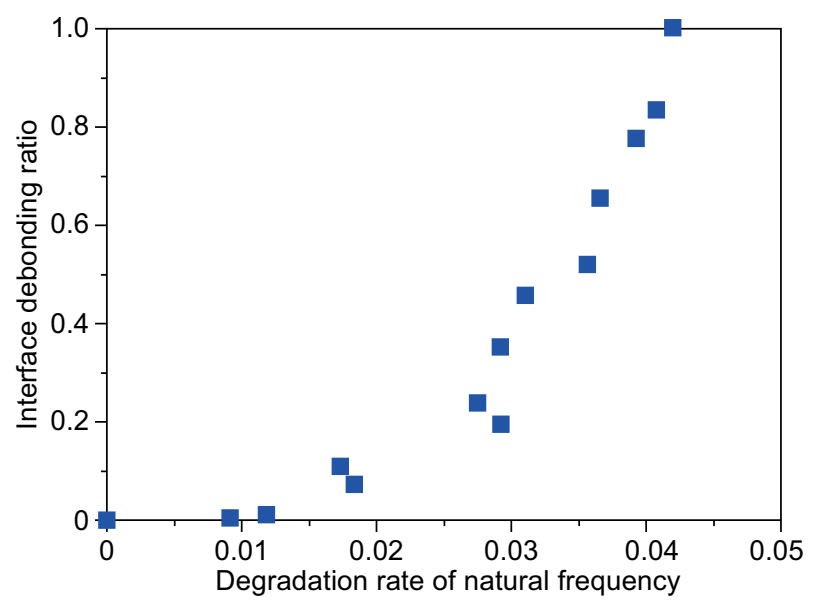

c)
- Stage III, which lines in the stress range from $\sigma_{\text {sat }}=$ $=215 \mathrm{MPa}$ to $\sigma_{\mathrm{uts}}=266.78 \mathrm{MPa}$. At this stage, the AE signal count and AE signal energy are relatively low and accompanied with a small amount of medium level energy release. Except for the high energy release in a short time, the frequency range of $\mathrm{AE}$ is wide, and the amplitude is low. This indicates that when some longitudinal fibers fracture, the material is in a stable state, except for a small amount of matrix crack propagation and fiber fracture, the sample has little damage until tensile fracture.

Figure 6 shows experimental and predicted cyclic loading/unloading hysteresis loops, degradation rate of composite modulus, interface debonding ratio, and broken fibers fraction versus degradation rate of natural frequency curves. Table 2 shows the evolution of natural frequency, composite modulus, interface debonding ratio and broken fibers fraction with loading stress.

Under low peak stresses of $\sigma_{\max }=48.5$ and 72.7 $\mathrm{MPa}$, the interface debonding length is less than the matrix crack spacing with the interface debonding

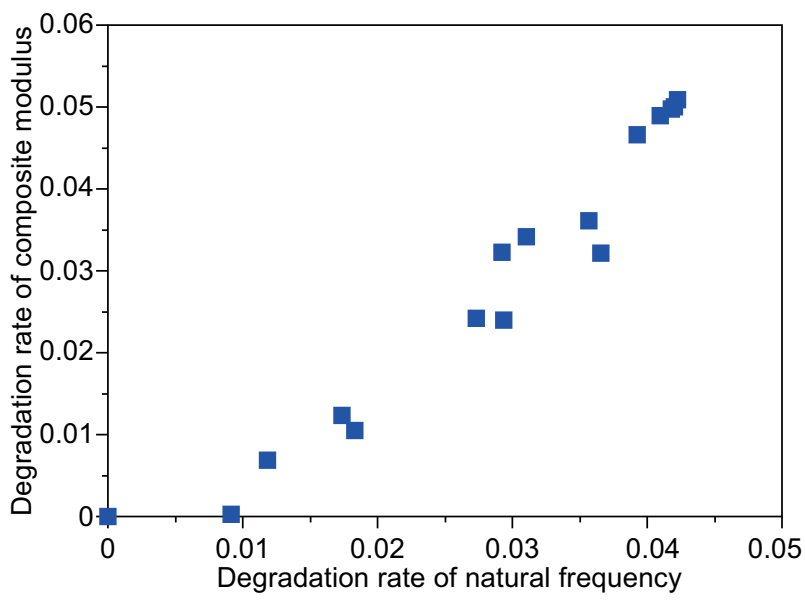

b)

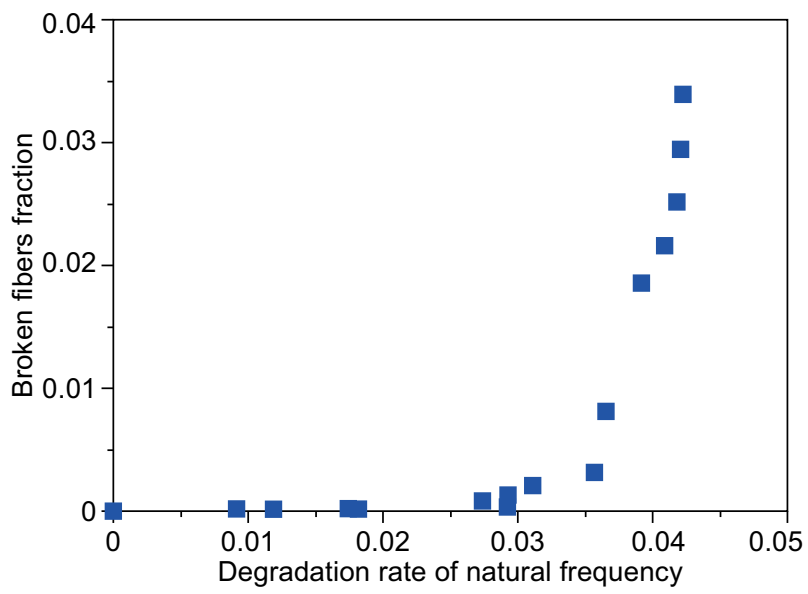

d)

Figure 6. Experimental and predicted cyclic loading/unloading hysteresis loops (a); the degradation rate of natural frequency versus degradation rate of composite modulus curve (b); the interface debonding ratio versus degradation rate of natural frequency curve (c) and the broken fibers fraction versus degradation rate of natural frequency curve of 2D SiC/SiC composite (d). 
Guo X., Wu J., Li J., Zeng Y., Huang X., Li L.

of $\eta=0.01$ and 0.07 . Upon unloading and reloading, the interface counter slip and new slip lengths approach the interface debonding tip, which indicates that the hysteresis loops under $\sigma_{\max }=48.5$ and $72.7 \mathrm{MPa}$ correspond to the interface partial debonding and the fiber sliding completely relative to the matrix in the interface debonding region.

Under peak stresses of $\sigma_{\max }=87.2,96.9,111.5$, $121.1,133.3,169.6,193.8$, and $198.7 \mathrm{MPa}$, the interface debonding length and interface debonding ratio increase with peak stress, i.e., from $\eta=0.11$ at $\sigma_{\max }=87.2 \mathrm{MPa}$ to $\eta=0.83$ at $\sigma_{\max }=198.7 \mathrm{MPa}$. Upon unloading and reloading, the interface counter slip and new slip lengths are less than the interface debonding length, which indicates that the hysteresis loops under $\sigma_{\max }=87.2$, 96.9, 111.5, 121.1, 133.3, 169.6, 193.8, and 198.7 MPa correspond to the interface partial debonding and the fiber sliding partial relative to the matrix in the interface debonding region.

Under peak stresses of $\sigma_{\max }=203.5,208.4$, and 213.2 $\mathrm{MPa}$, the interface debonding length approaches the matrix crack spacing, and the interface debonding ratio is $\eta=1.0$. Upon unloading and reloading, the interface counter slip and new slip lengths are less than the matrix crack spacing, which indicates that the hysteresis loops under $\sigma_{\max }=203.5,208.4$, and 213.2 MPa correspond to the interface complete debonding and the fiber sliding partial relative to the matrix in the interface debonding region.

When the peak stress increases to $\sigma_{\max }=213.2 \mathrm{MPa}$, the natural frequency decreases from $f_{0}=3415.6 \mathrm{~Hz}$ to 3271.5 , and the degradation rate of natural frequency is $\varphi=0.042$; the composite modulus decreases from $E_{\mathrm{c}}=$

Table 2. Evolution of natural frequency, composite modulus, interface debonding ratio, and broken fibers fraction with loading stress.

\begin{tabular}{rccll}
\hline $\begin{array}{r}\text { Stress } \\
(\mathrm{MPa})\end{array}$ & $\begin{array}{c}\text { Natural frequency } \\
(\mathrm{Hz})\end{array}$ & $\begin{array}{c}E_{\mathrm{c}} \\
(\mathrm{GPa})\end{array}$ & \multicolumn{1}{c}{$\eta$} & \multicolumn{1}{c}{$q$} \\
\hline 0.0 & 3415.6 & 162.8 & 0 & 0 \\
24.2 & 3384.4 & 162.2 & 0 & 0 \\
48.5 & 3375.0 & 151.5 & 0.01 & 0.000003 \\
72.7 & 3353.1 & 145.3 & 0.07 & 0.000049 \\
87.2 & 3356.3 & 142.3 & 0.11 & 0.000088 \\
96.9 & 3315.6 & 123.4 & 0.19 & 0.000275 \\
111.5 & 3321.9 & 123.4 & 0.24 & 0.000639 \\
121.1 & 3315.6 & 110.2 & 0.35 & 0.001050 \\
133.3 & 3309.4 & 107.1 & 0.46 & 0.001872 \\
145.4 & 3293.8 & 103.8 & 0.52 & 0.003163 \\
169.6 & 3290.6 & 110.4 & 0.65 & 0.008066 \\
193.8 & 3281.3 & 86.9 & 0.78 & 0.018433 \\
198.7 & 3275.9 & 83.1 & 0.83 & 0.021584 \\
203.5 & 3272.9 & 81.6 & 1 & 0.025134 \\
208.4 & 3271.9 & 80.7 & 1 & 0.029302 \\
213.2 & 3271.5 & 80.1 & 1 & 0.033999 \\
\hline
\end{tabular}

$=162.8$ to $80.1 \mathrm{GPa}$, and the degradation rate of composite modulus is $\psi=50.8 \%$; the interface debonding ratio increases to $\eta=1.0$; and the broken fibers fraction increases to $q=0.034$.

When the degradation rate of natural frequency is $\varphi=0.01$, matrix cracking and interface debonding occur, however, fibers failure does not appear; when the degradation rate of natural frequency is $\varphi=0.04$, the composite modulus decreases approximately $47 \%$ and the interface debonding ratio approaches $\eta=0.8$ and the broken fibers fraction is approximately $q=2.2 \%$.

\section{CONCLUSIONS}

In this paper, tensile damage and fracture of $2 \mathrm{D}$ $\mathrm{SiC} / \mathrm{SiC}$ composites were investigated using damage monitoring of $\mathrm{AE}$ and natural frequency. Nonlinear damage and fracture were mainly attributed to damage mechanisms of matrix cracking, interface debonding, and fibers fracture. Monotonic tensile stress-strain curves were divided into three stages based on the analysis of AE count, amplitude, and energy. Under cyclic loading/ unloading, hysteresis loops appeared due to internal frictional slip between the fiber and the matrix, and the natural frequency and composite modulus were obtained for different peak stress. A micromechanical tensile and cyclic loading/unloading constitutive model was adopted to predict the tensile curves. Micro damage parameters of interface debonding ratio and broken fibers fraction were used to characterize tensile damage and fracture. Relationships between natural frequency, composite modulus, interface debonding, and fibers fracture were established.

- Tensile stress-strain curve can be divided into three main stages corresponding to multiple damage mechanisms of matrix cracking, interface debonding, and fibers fracture. Under tensile loading, the AE signal was large and concentrated mainly in the stress range of $50-100 \mathrm{MPa}$ and $150-180 \mathrm{MPa}$, which corresponded to matrix cracking and fiber fracture, respectively.

- When the degradation rate of natural frequency was $\varphi=0.01$, matrix cracking and interface debonding occurred, however, fibers failure did not appear; when the degradation rate of natural frequency was $\varphi=0.04$, the composite modulus decreased approximately $47 \%$ and the interface debonding ratio approached $\eta=0.8$ and the broken fibers fraction was approximately $q=$ $2.2 \%$.

\section{Acknowledgements}

The work reported here is supported by the Fundamental Research Funds for the Central Universities (Grant No. NS2019038). 


\section{REFERENCES}

1. Naslain R. (2004): Design, preparation and properties of non-oxide CMCs for application in engines and nuclear reactors: an overview. Composites Science and Technology, 64(2), 155-170. doi: 10.1016/S0266-3538(03)00230-6

2. Li L.B. (2018). Damage, fracture and fatigue of ceramic-matrix composites. Springer Nature, Singapore. https:// www.springer.com/in/book/9789811317828

3. Li L.B. (2020). Durability of ceramic-matrix composites. Woodhead Publishing, Oxford, UK. doi: 10.1016/C2018-003346-0

4. Li L.B. (2019). Thermomechanical fatigue of ceramic-matrix composites. Wiley-VCH, Weinheim, Germany.

5. Li L.B. (2019): Modeling matrix multi-cracking evolution of fiber-reinforced ceramic-matrix composites considering fiber fracture. Ceramics-Silikáty, 63, 21-31. doi: 10.13168/ cs. 2018.0042

6. Li L.B. (2019): Temperature-dependent proportional limit stress of carbon fiber-reinforced silicon carbide ceramicmatrix composites. Ceramics-Silikáty, 63, 330-337. doi: 10.13168/cs.2019.0028

7. Wang Y., Zhang L., Cheng L., Mei H., Ma J. (2008): Characterization of tensile behavior of a two-dimensional woven carbon/silicon carbide composite fabricated by chemical vapor infiltration. Materials Science and Engineering A, 497, 295-300. doi: 10.1016/j.msea.2008.07.050
8. Li P., Wang B., Zhen W., Jiao G. (2014): Tensile loading/ unloading stress-strain behavior of $2 \mathrm{D}-\mathrm{SiC} / \mathrm{SiC}$ composites. Acta Materiae Compositae Sinica, 31, 676-682.

9. Liu H., Yang J.H., Jiao J. (2017): Fabrication technique and application prospect of continuous $\mathrm{SiC}$ fiber reinforced ceramic matrix composites for aeroengine. Aeronautical Manufacturing Technology, 16, 90-95.

10. Hu D., Zeng Y., Zhang L., Mei W., Shen X., Wang R. (2018): Effective elastic constants prediction and modal test of $2 \mathrm{D}$ braided $\mathrm{SiC} / \mathrm{SiC}$ ceramic matrix composites. Journal of Propulsion Technology, 39, 465-472.

11. Li L.B. (2020): A time-dependent vibration damping model of fiber-reinforced ceramic-matrix composites at elevated temperature. Ceramics International, 46, 27031-27045. doi: $10.1016 /$ j.ceramint.2020.07.180

12. Bai R., Chu J., Wang M., Chen H. (2005): Numerical prediction of frequency of delaminated advanced grid stiffened plate. Journal of Chongqing University, 28, 119-124.

13. Li H. (2019). Analysis of vibration and damage test of ceramic matrix composites structure. Master Thesis, Nanchang Hangkong University, Nanchang, China.

14. Li L.B. (2015): Cyclic loading/unloading hysteresis behavior of fiber-reinforced ceramic-matrix composites at room and elevated temperatures. Materials Science and Engineering A, 648, 235-242. doi: 10.1016/j.msea.2015.09. 090 